\title{
Treatment outcomes of HIV-positive patients on first-line antiretroviral therapy in private versus public HIV clinics in Johannesburg, South Africa
}

This article was published in the following Dove Press journal:

Clinical Epidemiology

18 March 2016

Number of times this article has been viewed

\author{
Faith Moyo' \\ Charles Chasela ${ }^{2,3}$ \\ Alana T Brennan ${ }^{1,4}$ \\ Osman Ebrahim ${ }^{5}$ \\ Ian M Sanne ${ }^{1,6}$ \\ Lawrence Long' \\ Denise Evans'
}

'Health Economics and Epidemiology Research Office, Department of Internal Medicine, School of Clinical Medicine, Faculty of Health Sciences, University of the Witwatersrand, Johannesburg, South Africa;

${ }^{2}$ Epidemiology and Biostatistics Department, School of Public Health, Faculty of Health Sciences, University of the Witwatersrand, Johannesburg, South Africa; ${ }^{3}$ Epidemiology and Strategic Information (ESI), HIV/ AIDS/STIs and TB, Human Sciences Research Council, Pretoria, South Africa; ${ }^{4}$ Center for Global Health and Development, Boston University, Boston, MA, USA; ${ }^{5}$ Brenthurst Clinic, Parktown, South Africa; ${ }^{6}$ Right to Care, Helen Joseph Hospital, Westdene, Johannesburg, South Africa

Correspondence: Faith Moyo Health Economics and Epidemiology Research Office, Department of Internal Medicine, School of Clinical Medicine, Faculty of Health Sciences, University of the Witwatersrand, Unit 2, 39 Empire Road, Parktown, Johannesburg, 2193, South Africa

Email faith.moyo@.yahoo.co.za
Background: Despite the widely documented success of antiretroviral therapy (ART), stakeholders continue to face the challenges of poor HIV treatment outcomes. While many studies have investigated patient-level causes of poor treatment outcomes, data on the effect of health systems on ART outcomes are scarce.

Objective: We compare treatment outcomes among patients receiving HIV care and treatment at a public and private HIV clinic in Johannesburg, South Africa.

Patients and methods: This was a retrospective cohort analysis of ART naïve adults ( $\geq 18.0$ years), initiating ART at a public or private clinic in Johannesburg between July 01, 2007 and December 31, 2012. Cox proportional-hazards regression was used to identify baseline predictors of mortality and loss to follow-up ( $>3$ months late for the last scheduled visit). Generalized estimating equations were used to determine predictors of failure to suppress viral load ( $\geq 400$ copies $/ \mathrm{mL}$ ) while the Wilcoxon rank-sum test was used to compare the median absolute change in CD4 count from baseline to 12 months post-ART initiation.

Results: 12,865 patients initiated ART at the public clinic compared to 610 at the private clinic. The patients were similar in terms of sex and age at initiation. Compared to public clinic patients, private clinic patients initiated ART at higher median CD4 counts (159 vs 113 cells $/ \mathrm{mm}^{3}$ ) and World Health Organization stage I/II (76.1\% vs 58.5\%). Adjusted hazard models showed that compared to public clinic patients, private clinic patients were less likely to die (adjusted hazard ratio [aHR] 0.50; 95\% confidence interval [CI] 0.35-0.70) but were at increased risk of loss to follow-up (aHR 1.80; 95\% CI 1.59-2.03). By 12 months post-ART initiation, private clinic patients were less likely to have a detectable viral load (adjusted relative risk 0.65 ; 95\% CI $0.49-0.88$ ) and recorded higher median CD4 change from baseline (184 cells $/ \mathrm{mm}^{3}$ interquartile range 101-300 vs 158 cells $/ \mathrm{mm}^{3}$ interquartile range 91-244), when compared to public clinic patients.

Conclusion: We identified differences in treatment outcomes between the two HIV clinics. Findings suggest that the type of clinic at which ART patients initiate and receive treatment can have an impact on treatment outcomes. Further research is necessary to provide more conclusive results.

Keywords: health systems, attrition, HIV programs, viral suppression

\section{Introduction}

Adherence to treatment and patient retention in care are key to achieving good treatment outcomes in HIV care and management. ${ }^{1,2}$ In South Africa, HIV care is provided by both the public and private sector. Like in most developing countries, the private sector has a long history of antiretroviral therapy (ART) provision through donor-funded projects. Over the years, the public sector has become the major 
provider of HIV care, resulting in the country having the largest free ART program globally. ${ }^{3}$ The provision of ART in the public sector is prescribed by the South African Deparment of Health (DoH) National ART treatment guidelines adapted from the World Health Organization (WHO). Health care providers in the private sector can use the South African DoH National ART treatment guidelines but it is not mandatory (Table 1). Initiation criteria and treatment are generally the same; however, the private sector has access to different drugs which are usually more expensive. ${ }^{4}$

Given the foregoing, there are challenges to the attainment of desired treatment outcomes, some unique to either sector. Health system factors include: clinical mismanagement, poor quality of HIV care, lack of standardization, and poor regulation of services. ${ }^{3,4}$ There are concerns of poor monitoring of HIV care and desired treatment outcomes in both sectors, particularly in the private sector where practitioners are often unregulated. ${ }^{3}$ These factors have a negative impact on treatment, leading to poorer treatment outcomes like mortality, and increased the risk of loss to follow-up (LTF). Attrition is more common in private clinics. ${ }^{4,5}$ The high costs of HIV drugs in this sector are identified as one of the driving factors of poor adherence to treatment and subsequent LTF. This suggests that patients in private clinics have a higher risk of developing viral resistance due to treatment interruptions than those in public clinics. ${ }^{5}$ The public sector has its fair share of challenges. The overwhelming work load compromises the quality of HIV care, ${ }^{6,7}$ for example, counseling sessions are reduced or not done at all ${ }^{5}$ and the quality of counseling has been identified as a risk factor for patient retention in ART care. ${ }^{6}$ Lengthy queues at the clinic may deter patients from accessing drugs. Stigmatization, ${ }^{6}$ also common in the public sector, often leads to nonadherence to treatment and high rates of LTF. $^{5}$

Extensive studies have been done to assess HIV treatment outcomes in the public sector, ${ }^{8-10}$ however, data on the differences in treatment outcomes between the public and private health care setting is scarce. Therefore, this study aimed to describe patients seeking care at a private or public HIV clinic in Johannesburg. We described differences in mortality, LTF, and viral suppression during early ART initiation ( $<12$ months) where differences were most likely to be observed. We compared treatment outcomes and identified baseline predictors of all-cause mortality, LTF, failure to suppress viral load ( $\geq 400$ copies $/ \mathrm{mL}$ ), and CD4 count change at 12 -month post-ART initiation.

\section{Patients and methods Study site and subjects}

A retrospective cohort study design was used to analyze routinely collected data from a public sector and a private sector HIV clinic. The Themba Lethu Clinic (TLC), representative

Table I Comparative description of study sites

\begin{tabular}{|c|c|c|}
\hline Characteristic & Private clinic & Themba Lethu Clinic \\
\hline \multicolumn{3}{|l|}{ Demographics } \\
\hline Clinic size & $\begin{array}{l}\text { Single HIV clinician who sees on average } \\
25 \text { patients per day }\end{array}$ & $\begin{array}{l}\text { Modest medical staff complement of approximately } \\
6-8 \text { doctors that see approximately } 400-500 \text { patients per } \\
\text { day ( } 50-60 \text { patients per doctor per day) }\end{array}$ \\
\hline $\begin{array}{l}\text { Characteristics } \\
\text { of the patients }\end{array}$ & $\begin{array}{l}\text { Most patients are educated and gainfully employed } \\
\text { ( } 79 \% \text { and } 86 \% \text {, respectively). All patients are on medical } \\
\text { aid. Cash patients are usually foreign }\end{array}$ & $\begin{array}{l}53 \% \text { of patients are unemployed although the majority } \\
\text { have above primary-level education }\end{array}$ \\
\hline \multicolumn{3}{|l|}{ HIV management } \\
\hline $\begin{array}{l}\text { ART initiation } \\
\text { criteria }\end{array}$ & $\begin{array}{l}2004 \text { WHO guidelines }{ }^{12} \\
\text { Eligibility: CD4 cell count } \leq 200 / \mathrm{mm}^{3} \text {, regardless of } \\
\text { WHO stage or WHO stage IV irrespective of CD4 count } \\
\text { First-line regimen: AZT-3TC/NVP } \\
20 \text { I0 WHO guidelines }{ }^{13} \\
\text { Eligibility: patients initiated with a CD4 } \\
\text { cell count } \leq 350 \text { cells } / \mathrm{mm}^{3} \text { or WHO stage III or IV, } \\
\text { coinfected with tuberculosis (TB) or hepatitis B virus (HBV) } \\
\text { irrespective of CD } 4 \text { cell count } \\
\text { First-line regimen: AZT/3TC/EFV or TDF/3TC/EFV } \\
\text { (or NVP in place of EFV) }\end{array}$ & $\begin{array}{l}2004 \text { South African DoH National ART treatment } \\
\text { guidelines }{ }^{14} \\
\text { Eligibility: CD4 cell count next } 200 / \mathrm{mm}^{3} \text {, regardless of } \\
\text { WHO stage or WHO stage IV irrespective of CD4 count } \\
\text { First-line regimen: d4T/3TC/EFV or } \mathrm{d} 4 \mathrm{~T} / 3 \mathrm{TC} / \mathrm{NVP} \\
20 \text { I0 South African DoH National ART treatment } \\
\text { guidelines }{ }^{15} \text { prior to April of the same year } \\
\text { Eligibility: CD4 cell count }<200 \text { cells } / \mathrm{mm}^{3} \text { irrespective of } \\
\text { clinical stage or CD4 count } \leq 350 \text { cells } / \mathrm{mm}^{3} \text { in patients } \\
\text { coinfected with TB or pregnant women or WHO stage } \\
\text { IV irrespective of CD4 count } \\
\text { First-line regimen: TDF and } 3 T C \text { or FTC with EFV or NVP }\end{array}$ \\
\hline ART monitoring & $\begin{array}{l}\text { Viral load, AST, ALT, and CD } 4 \text { count tests are collected } \\
\text { every } 3-4 \text { month visit }\end{array}$ & $\begin{array}{l}\text { Viral load, AST, ALT, and CD4 count tests are collected } \\
\text { at } 4-7 \text { months after initiation of a new regimen, } \\
\text { thereafter biannual or as clinically indicated }\end{array}$ \\
\hline
\end{tabular}

Abbreviations: ART, antiretroviral therapy; DoH, Department of Health; 3TC, lamivudine; NVP, nevirapine; WHO, World Health Organization; AZT, zidovudine; d4T, stavudine; EFV, efavirenz; TDF, tenofovir; FTC, emtricitabine; AST, aspartate transaminase; ALT, alanine transaminase. 
of the public sector, is located in the city of Johannesburg, Gauteng Province in North Central South Africa. Gauteng Province has an estimated HIV prevalence of $15.2 \%$ and has the second largest number of patients on ART in South Africa. The clinic is located in an ambulatory care wing of the Helen Joseph Hospital, a large urban public sector teaching hospital. The TLC is one of the largest comprehensive care, management, and treatment (CCMT) sites in South Africa and provides both pre-ART and ART care. ${ }^{11}$ Since 2004, TLC has enrolled approximately 36,487 HIV-positive patients into its HIV care and treatment program. Approximately, 400-500 patients are seen per day by a modest clinical staff for medical and/or ART visits. There are six to eight full-time doctors, nine nurses, three pharmacists, and a team of five administrative and eight data entry staff (Table 1). Current numbers are down on earlier numbers following down referral to clinics and general practitioners (GPs) in the area.

The private clinic is located in Brenthurst, Parktown, Johannesburg. The clinic provides private HIV care and treatment where patients pay for services and drugs either by cash or through medical-aid schemes. The clinic has been operational since 2007 and is managed by a single HIV clinician. By December 2012, the clinic had enrolled approximately 3,857 patients on ART. On average, 25 patients are seen per day at this clinic.

The study included ART naïve HIV-positive adults eligible for ART initiation according to either the WHO guidelines ${ }^{12,13}$ or the South African DoH National ART treatment guidelines ${ }^{14,15}$ and initiated on standard first-line ART between July 1, 2007 and December 1, 2012 ${ }^{12}$ (Table 1). Prior to April 2010, eligibility for ART required a CD4 count of $\leq 200 \mathrm{cells} / \mathrm{mm}^{3}$. This has since risen to $\leq 350$ cells $/ \mathrm{mm}^{3} .{ }^{3}$ The patients were given a first-line regimen recommended by the WHO consisting of two nucleoside reverse transcriptase inhibitors (stavudine, lamivudine, and tenofovir were introduced after 2010) and one nonnucleoside transcriptase inhibitor (efavirenz).,12-16 However, stavudine was prescribed minimally at the private clinic.

We excluded patients who transferred into either clinic from other sites, minors ( $<18.0$ years of age), those who initiated ART outside the study period, treatment-experienced patients, and pregnant females. We excluded pregnant at ART initiation as pregnant women are typically placed on the boosted protease inhibitor Kaletra (lopinavir and ritonavir) while nonpregnant women with declared pregnancy intentions at baseline are placed on nevirapine rather than efavirenz. ${ }^{17}$ In addition, we excluded transfer-ins (patients who transferred on ART into either clinic) as these patients generally do not have a record of earlier ART or baseline clinical or laboratory information at ART initiation.

\section{Data collection and management}

Data are collected from each site's routinely maintained electronic medical records, which are entered and stored in an information system called TherapyEdge-HIV ${ }^{\text {TM }}$ (Associated Biological Systems, Johannesburg, South Africa). For this study, paper-based medical records kept by the sites were used to supplement the electronic medical record system as needed. Patient information collected at ART initiation includes demographics (ie, sex, age, and employment) and clinical data (medical diagnoses, treatment regimens, and laboratory results) ${ }^{11}$ Longitudinal clinical and laboratory data (CD4 counts, viral load), regimen changes, and other medical investigations are collected at each medical visit.

CD4+ T-cell lymphocyte counts are done using panleucogated CD4+ flow cytometry (FlowCount Fluorospheres, Beckman Coulter-Immunotech, Villepinte, France) while HIV-1 RNA viral load tests are performed using NucliSENSEasyQ ${ }^{\circledR}$ HIV-1 assay (bioMérieux Clinical Diagnostics, Marcy l'Etoile, France). At TLC, treatment monitoring is done using CD4 counts and viral load tests between 4 and 7 months after initiation of a new regimen, thereafter at 6-month intervals or as clinically indicated under the 2004 HIV guidelines. ${ }^{14}$ However, as of April 2010, the monitoring schedule was shifted to 6 months after ART initiation and yearly thereafter..$^{15}$ At the private clinic, monitoring is done every 3-4 months since the last scheduled visit or as clinically indicated. The National Health Laboratory Services (NHLS) are contracted to conduct laboratory services for TLC while the private clinic uses a private laboratory called AMPATH/ Lancet Laboratory, a private pathology service available throughout South Africa.

The patients collect their antiretroviral drugs monthly or every 2 months when stable. Information is available on ART treatment outcomes including death, LTF (defined as failure to attend the clinic for more than 3 months since the last scheduled visit), and transfer or down referral to another facility. At both facilities, patients who miss scheduled visit dates are actively traced telephonically and misclassification is reduced by linking patients with a valid South African ID number to the South African National Vital Registration System to update their death status. ${ }^{8}$ The most recent linkage, for all sites using the electronic patient management system (TherapyEdge-HIVTM; $n=10$ ), was conducted in April 2013 for research purposes.

The main exposure variable of the study was the type of clinic (private vs public) in which patients initiated ART. Sociodemographic variables and biological variables such as CD4 count and WHO clinical staging at ART initiation were also assessed. Body mass index (BMI; $\left.\mathrm{kg} / \mathrm{m}^{2}\right)$ was used as a proxy for the nutritional status of patients at ART initiation. 
Anemia was then categorized according to WHO guidelines as none $(\mathrm{Hb} \geq 12.0 \mathrm{~g} / \mathrm{dL}$ for nonpregnant women and $\mathrm{Hb} \geq 13.0 \mathrm{~g} / \mathrm{dL}$ for men), mild (Hb 11.0-11.9 g/dL for nonpregnant women and $11.0-12.9 \mathrm{~g} / \mathrm{dL}$ for men), moderate $(8.0-10.9 \mathrm{~g} / \mathrm{dL})$, and severe $(\mathrm{Hb}<8.0 \mathrm{~g} / \mathrm{dL}) .{ }^{16}$ The WHO stage was determined either by physician classification or by conditions present at ART initiation.

The outcomes of the study included all-cause mortality and LTF, failure to suppress viral load ( $\geq 400$ copies $/ \mathrm{mL}$ ) and CD4 count change (absolute difference in CD4 count from baseline to 12 months on treatment) at 12-month post-ART initiation. In patients that were alive and in care at 12-month post-ART initiation, the viral load or CD4 count results closest to 12 months but within 9 and 15 months of ART initiation were used in the analysis. We conducted a sensitivity analysis for those with a missing viral load at 12-month post-ART. In the first scenario, everyone with a missing value was assigned viral load $<400$ copies $/ \mathrm{mL}$ while in the second scenario everyone with a missing value was assigned viral load $\geq 400$ copies $/ \mathrm{mL}$.

\section{Statistical analysis}

The data were exported from TherapyEdge-HIVTM into SAS 9.1 (SAS Institute Inc., Cary, NC, USA) and STATA $11^{\mathrm{TM}}$ StataCorp LP (College Station, TX, USA) for the analysis. Baseline demographic, clinical, and immunological characteristics of patients at ART initiation at either clinic were compared. Continuous variables were described using means and standard deviations (parametric data) or medians and interquartile range (IQR; nonparametric data) and compared using Student's $t$-tests and Wilcoxon rank-sum test (MannWhitney), respectively. Categorical data were described using proportions and compared using Pearson's chi-square or Fischer's exact for sparse data.

Kaplan-Meier estimates were used to compare mortality and LTF between the two clinics. Cox proportional-hazard regression was used to identify predictors of mortality and LTF. Person-time started at ART initiation and ended at the earliest date of death, LTF, transfer, completion of 12 months of follow-up, or dataset closure (12/2013). Univariate analysis was used to select variables that were significant determinants of treatment outcomes at the $P<0.20$ level of significance. These significant variables were then used to build the adjusted multivariate models. Confounding and effect modification were assessed using the MantelHaenszel method. Log-likelihood ratio tests were used to select the final model using an likelihood ratio chi-squared test $P \leq 0.05$. The assumption of proportionality of hazards was checked using Cox-Snell residual plots and Schoenfield residuals tests.
Proportions were used to describe a virological response at 12-month post-ART initiation between the two facilities. Generalized estimating equations were used to assess predictors of failure to suppress viral load. Models were built and diagnostic tests performed as described earlier. The Wilcoxon rank-sum test was used to compare median absolute differences in CD4 count from baseline to 12-month postART initiation. Median change was calculated by subtracting the baseline CD4 count measurement from the CD4 count value at 12 months on ART.

This study was approved by the Human Research Ethics Committee of the University of the Witwatersrand (protocol number M120863), and no patient consent was required by the committee, as all patient records/information were anonymized and de-identified prior to analysis.

\section{Results}

\section{Baseline characteristics of the cohort}

A total of 12,865 patients for the public and 610 patients for the private clinic were included in the analysis (Figure 1). Patients from the public clinic were similar to those in the private clinic in terms of sex, age at ART initiation, however, they were different in terms of CD4 count, educational level, employment status, WHO stage, initiating regimens, and nutritional status at baseline (Table 2). As expected, a higher proportion of private clinic patients were employed ( $86.4 \%$ vs $53.4 \%$ ), presented earlier for ART initiation (WHO stages I or II 76.1\% vs 58.5\%), and recorded a higher median CD4 count 159 vs 113 cells/ $\mathrm{mm}^{3}$ compared to the public clinic. However, patients enrolled in the public clinic recorded higher median BMI (BMI: 23.4 vs $21.6 \mathrm{~kg} / \mathrm{m}^{2}$ ) compared to their counterparts.

\section{Mortality at 12 months of ART}

After 12 months on ART, 1,382/13,475 (10.3\%) patients died in a median (IQR) follow-up of $0.4(0.33-0.67)$ years. The overall incidence rate of mortality was 43 deaths/1,000 person years (pys), and (44 vs 20/1,000 pys; $P<0.001$ ) stratified by clinic, respectively (public vs private). The risk of death was higher in the first 12 months of initiating ART for both facilities ( 91 vs $45 / 1,000$ pys; $P<0.001$ ), decreasing steadily with prolonged exposure to ART.

The type of clinic was found to be a significant predictor of mortality (Table 3). After adjusting for other covariates, private clinic patients had a lower risk of mortality compared to those in the public clinic (adjusted hazard ratio; aHR 0.50; $95 \%$ confidence interval [CI] 0.35-0.70). The risk of death increased with an increase in age at initiation. Patients aged above 50 years were almost two times more likely to die compared to young adults (18-29.9 years) (aHR 1.86; 95\% 


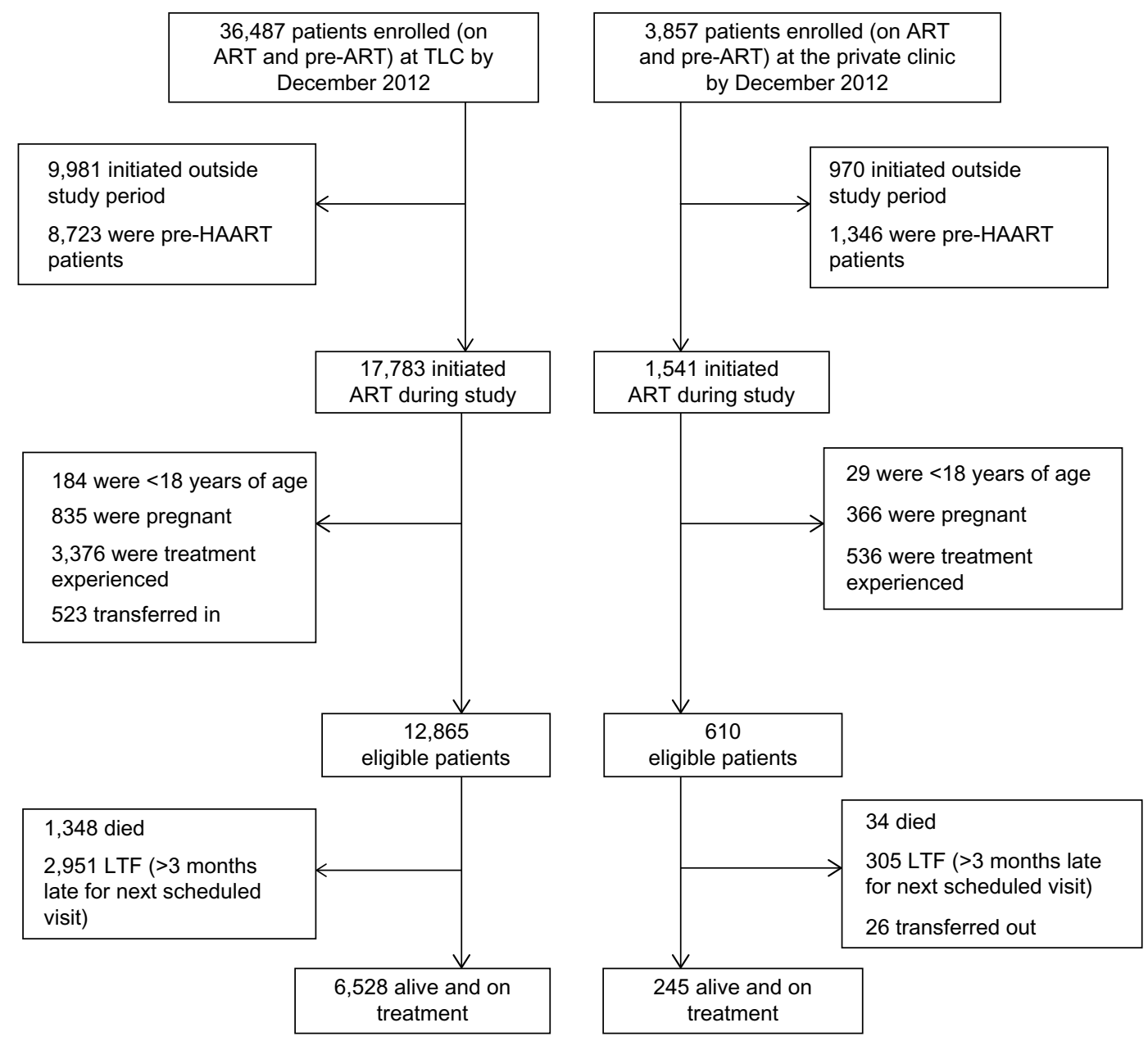

Figure I Cohort profile stratified by clinic type in December 2012 .

Notes: This figure is a structured flow chart of how the final eligible study cohort was obtained from the original datasets from each clinic. It also shows the ART program losses (mortality and LTF) of each health facility.

Abbreviations: ART, antiretroviral therapy; TLC, Themba Lethu Clinic; HAART, highly active antiretroviral therapy; LTF, loss to follow-up.

CI 1.53-2.25). Males were more likely to die compared to females (aHR 1.20; 95\% CI 1.07-1.34).

Patients initiating ART late (WHO stage III or IV) were more likely to die compared to those initiating treatment at the early stage of HIV (WHO stage I or II) (aHR 1.52; 95\% CI 1.37-1.70). Initiating ART with a high CD4 count was protective against mortality as shown in Table 3 . Underweight $\left(\mathrm{BMI}<18.5 \mathrm{~kg} / \mathrm{m}^{2}\right.$ ) patients at ART initiation were 1.8 times more likely to die compared to patients with a normal weight $\left(\mathrm{BMI} \geq 18.5 \mathrm{~kg} / \mathrm{m}^{2}\right)$ (aHR 1.76; 95\% CI 1.58-1.98). Similarly, patients with severe anemia (hemoglobin $<8.0 \mathrm{~g} / \mathrm{dL}$ ) had a $50 \%$ greater risk of dying compared to those without anemia (aHR 1.47; 95\% CI 1.31-1.64).

\section{Loss to follow-up at 12 months of ART} Incidence rates were 95 vs 180 per 1,000 pys $(P<0.001)$, respectively, in the public and private clinic, respectively. Patients who initiated ART in the private sector were more likely to be LTF (aHR 1.80; 95\% CI 1.59-2.03; Table 3). Older patients were more likely to be retained on ART compared to young adults. For example, the $\geq 50$ age group were less likely to be lost from the program compared to the 18-29 age group (aHR 0.70; 95\% CI 0.61-0.80). Among the cohort, male vs female patients (aHR 1.45; 95\% CI 1.35-1.55), and those with severe anemia (aHR 1.61; 95\% CI 1.49-1.73) or low BMI $<18.5 \mathrm{~kg} / \mathrm{m}^{2}$ (aHR 1.35; 95\% CI $1.25-1.45)$ were at increased risk of being lost from care. In addition, lower CD4 count and less than primary level education were also significant predictors.

\section{Immunological and virological responses to ART at 12 months of ART}

By 12-month post-ART initiation, immunological and virological responses to ART were different between the clinics. A total of 10.5\% $(1,348 / 12,865)$ and 5.6\% (34/610) in the public and private clinic had a detectable viral load at 
Table 2 Baseline characteristics of HIV-positive patients on firstline antiretroviral therapy patients, stratified by clinic

\begin{tabular}{|c|c|c|}
\hline Characteristic & Public, $N=\mid 2,865$ & Private, $N=610$ \\
\hline \multicolumn{3}{|l|}{ Sex } \\
\hline Female & 7,644 (59.4\%) & 358 (58.7\%) \\
\hline Male & 5,221 (40.6\%) & $252(41.3 \%)$ \\
\hline \multicolumn{3}{|l|}{ Age at initiation (years) } \\
\hline Median (IQR) & $37.4(31.7-44.2)$ & $36.9(32.4-40.0)$ \\
\hline $18-29.9$ & 2,331 (I8.1\%) & $78(12.8 \%)$ \\
\hline $30-39.9$ & $5,484(42.6 \%)$ & $326(53.4 \%)$ \\
\hline $40-49.9$ & $3,498(27.2 \%)$ & 157 (25.8\%) \\
\hline$\geq 50$ & I,552 (12.1\%) & $49(8.0 \%)$ \\
\hline \multicolumn{3}{|l|}{ Education } \\
\hline $\begin{array}{l}\text { Above primary level } \\
(\geq \text { Grade } 8)\end{array}$ & II,206 (87.1\%) & $48 I$ (78.9\%) \\
\hline $\begin{array}{l}\text { Below primary level } \\
(<\text { Grade } 8)\end{array}$ & 467 (3.6\%) & $4(0.7 \%)$ \\
\hline Unknown & I, 192 (9.3\%) & 125 (20.4\%) \\
\hline \multicolumn{3}{|l|}{ Employment } \\
\hline Employed & $6,866(53.4 \%)$ & 527 (86.4\%) \\
\hline Unemployed & 5,999 (46.6\%) & $83(13.6 \%)$ \\
\hline \multicolumn{3}{|c|}{ CD4 count (cells $/ \mathrm{mm}^{3}$ blood) } \\
\hline Median (IQR) & II3 (43-189) & $159(66-251)$ \\
\hline$\leq 100$ & 3,953 (30.7\%) & 97 (I5.9\%) \\
\hline $10 \mid-200$ & 4,054 (3I.5\%) & $159(26.1 \%)$ \\
\hline $20 I-350$ & 2,504 (19.5\%) & $276(45.2 \%)$ \\
\hline Missing & $2,354(18.3 \%)$ & $78(12.8 \%)$ \\
\hline \multicolumn{3}{|l|}{ Log viral load } \\
\hline Mean (SD) & $9.9(2.5)$ & $10.5(2.4)$ \\
\hline \multicolumn{3}{|l|}{ BMI $\left(\mathrm{kg} / \mathrm{m}^{2}\right)$} \\
\hline$\geq 18.5$ & 8,755 (68.1\%) & $306(50.2 \%)$ \\
\hline$<18.5$ & $2,574(20.0 \%)$ & 199 (32.6\%) \\
\hline Missing & I,536 (II.7\%) & 105 (I7.2\%) \\
\hline \multicolumn{3}{|l|}{ Hemoglobin $(g / d L)$} \\
\hline No anemia & $2,844(22.1 \%)$ & 172 (28.2\%) \\
\hline Mild anemia & $3,087(24.0 \%)$ & $186(30.5 \%)$ \\
\hline Moderate anemia & $4,323(33.6 \%)$ & $169(27.7 \%)$ \\
\hline Severe anemia & 939 (7.3\%) & $30(4.9 \%)$ \\
\hline Missing & $1,672(13.0 \%)$ & $53(8.7 \%)$ \\
\hline \multicolumn{3}{|l|}{$\mathrm{WHO}$ stage } \\
\hline Stage I or II & 7,525 (58.5\%) & $464(76.1 \%)$ \\
\hline Stage III or IV & $4,260(33.1 \%)$ & 107 (17.5\%) \\
\hline Missing & $\mathrm{I}, 080$ (8.4\%) & $39(6.4 \%)$ \\
\hline \multicolumn{3}{|l|}{ Baseline ART regimen } \\
\hline 3TC/TDF/EFV & 4,786 (37.2\%) & $26(4.3 \%)$ \\
\hline $\mathrm{d} 4 \mathrm{~T} / 3 \mathrm{TC} / \mathrm{EFV}$ & $5,44 \mid(42.3 \%)$ & $4(0.7 \%)$ \\
\hline TDF/3TC/FTC & I,004 (7.8\%) & $232(38.0 \%)$ \\
\hline LPV/r/AZT/3TC & $\mathrm{I}, 634(12.7 \%)$ & $348(57.1 \%)$ \\
\hline \multicolumn{3}{|l|}{ 12-month outcomes } \\
\hline Alive and in care & $6,528(50.7 \%)$ & $245(40.2 \%)$ \\
\hline Dead & I,348 (I0.5\%) & $34(5.6 \%)$ \\
\hline Loss to follow-up & $2,95 \mathrm{I}(22.9 \%)$ & $305(50.0 \%)$ \\
\hline Transferred out & 2,038 (I5.9\%) & $26(4.2 \%)$ \\
\hline
\end{tabular}

Abbreviations: IQR, interquartile range; BMI, body mass index; WHO, World Health Organization; ART, antiretroviral therapy; 3TC, lamivudine; TDF, tenofovir; EFV, efavirenz; d4T, stavudine; FTC, emtricitabine; LPV/r, lopinavir/ritonavir; AZT, zidovudine; SD, standard deviation.

12 months. Among those with a viral load at 12 months, private clinic patients were less likely to have a detectable viral load (adjusted relative risk $[\mathrm{aRR}]=0.65 ; 95 \% \mathrm{CI} 0.49-0.88$; Table 4 ). Compared to females, males had a greater risk of having a detectable viral load at 12-month post-ART initiation (aRR 1.36; 95\% CI 1.22-1.52). Similarly, underweight patients were more likely to have a detectable viral compared to patients with normal weight at baseline (aRR 1.23; 95\% CI 1.09-1.39).

Among those alive and in care at 12 months, 45.0\% $(2,938 / 6,528)$ of the public clinic patients had a viral load at 12 months compared to $55.1 \%(135 / 245)$ patients at the private clinic. We conducted a sensitivity analysis to investigate the effect of missing viral load values on the inference estimates for our main exposure (ie, clinic type). We did not observe a difference in the direction of the effect of the exposure on virological outcomes at 12-month post-ART initiation, however, estimates were biased toward the null. That is unadjusted RR [uRR] 0.86; 95\% CI 0.64-1.16, when missing values were assigned a viral load $<400$ copies $/ \mathrm{mL}$ and uRR 0.83 ; 95\% CI $0.77-0.90$ when missing values were assigned a viral load $\geq 400$ copies $/ \mathrm{mL}$.

The median CD4 change from baseline to 12 months of treatment was different between the sites, that is, median CD4 count change of 158 cells $/ \mathrm{mm}^{3}$ (IQR 91-244) vs 184 cells $/ \mathrm{mm}^{3}$ (IQR $101-300$ ) in the public and private clinic $(P<0.001)$, respectively. The proportion of patients with a CD4 change from baseline to 12-month post-ART initiation of less than 100 cells $/ \mathrm{mm}^{3}$ was $3.2 \%$ for the private and $5.4 \%$ for the public clinic, respectively.

\section{Discussion}

We compared treatment outcomes, specifically all-cause mortality, LTF, failure to suppress viral load, and CD4 count change, among patients receiving HIV care and treatment at a public or private HIV clinic in Johannesburg, South Africa. In our study, we identified differences in treatment outcomes among study participants; mortality rates were found to be higher in the public clinic compared to the private clinic (44 vs $20 / 1,000$ pys; $P<0.001)$. However, LTF rates were lower in the public clinic (95 vs $180 / 1,000$ pys; $P<0.001$ ). Patients receiving treatment in the private clinic had better immunological and virological outcomes at 12 months of ART.

We identified baseline predictors of all-cause mortality, LTF, failure to suppress viral load ( $\geq 400$ copies/mL), and CD4 count change at 12 -month post-ART initiation. The type of health facility in which patients received ART care, age at ART initiation, sex and baseline CD4 count, and nutritional status at baseline were identified as some of the significant predictors of treatment outcomes at 12 months on ART.

\section{Mortality}

Our findings showed that initiating treatment in the private clinic was protective against mortality. A South African 
Table 3 Predictors of mortality and loss to follow-up at 12 months of ART among the cohort during the study period (July 2007December 2012)

\begin{tabular}{|c|c|c|c|c|c|c|}
\hline \multirow{2}{*}{$\begin{array}{l}\text { Factors at } \\
\text { baseline }\end{array}$} & \multicolumn{3}{|l|}{ Mortality } & \multicolumn{3}{|l|}{ Loss to follow-up } \\
\hline & $\begin{array}{l}N^{2}=1382, \text { data } \\
\text { shown as } n / N(\%)\end{array}$ & $\begin{array}{l}\text { Crude HR, } \\
(95 \% \mathrm{Cl})\end{array}$ & $\begin{array}{l}\text { Adjusted } \\
\text { HR, }(95 \% \mathrm{Cl})\end{array}$ & $\begin{array}{l}N^{\mathrm{b}}=3,256, \text { data } \\
\text { shown as } \mathrm{n} / \mathrm{N}(\%)\end{array}$ & $\begin{array}{l}\text { Crude HR } \\
(95 \% \mathrm{Cl})\end{array}$ & $\begin{array}{l}\text { Adjusted HR } \\
(95 \% \mathrm{Cl})\end{array}$ \\
\hline \multicolumn{7}{|l|}{ Health facility } \\
\hline Public & $\mathrm{I}, 348 / \mathrm{I} 2,865(\mathrm{I} 0.5)$ & Reference & Reference & $2,95 \mathrm{I} / \mathrm{I} 2,865$ (22.9) & Reference & Reference \\
\hline Private & $34 / 610(5.6)$ & $0.49(0.35-0.69)$ & $0.50(0.35-0.70)$ & $305 / 610(50.0)$ & $1.91(1.69-2.15)$ & $1.80(1.59-2.03)$ \\
\hline \multicolumn{7}{|l|}{ Age at initiation (years) } \\
\hline 18-29.9 & $206 / 2,409(8.6)$ & Reference & Reference & $710 / 2,409(29.5)$ & Reference & Reference \\
\hline $30-39.9$ & $55 \mathrm{I} / 5,810(9.5)$ & $1.08(0.92-1.27)$ & $1.09(0.93-1.28)$ & $\mathrm{I}, 4|7 / 5,8| 0(24.4)$ & $0.79(0.73-0.87)$ & $0.77(0.70-0.86)$ \\
\hline $40-49.9$ & $393 / 3,655(10.8)$ & $1.24(1.05-1.47)$ & $1.32(\mathrm{I} .1 \mathrm{I}-\mathrm{I} .57)$ & $803 / 3,655$ (2I.9) & $0.73(0.66-0.8 \mathrm{I})$ & $0.72(0.65-0.80)$ \\
\hline$\geq 50$ & $232 / 1,601(14.5)$ & $1.74(1.45-2.1 \mathrm{I})$ & $1.86(1.53-2.25)$ & $326 / I, 60 I(20.4)$ & $0.73(0.64-0.83)$ & $0.70(0.6 \mathrm{I}-0.80)$ \\
\hline \multicolumn{7}{|l|}{ Sex } \\
\hline Female & $737 / 8,002(9.2)$ & Reference & Reference & $\mathrm{I}, 726 / 8,002$ (2I.6) & Reference & Reference \\
\hline Male & 645/5,473 (1I.8) & $1.34(1.21-1.49)$ & $1.20(1.07-1.34)$ & I,530/5,473 (27.9) & $1.40(1.31-1.50)$ & $1.45(1.35-1.55)$ \\
\hline \multicolumn{7}{|l|}{ Employment } \\
\hline Unemployed & $642 / 6,082(10.6)$ & Reference & Reference & $\mathrm{I}, 62 \mathrm{I} / 6,082(26.7)$ & Reference & Reference \\
\hline Employed & 740/7,393 (10.0) & $0.67(0.60-0.74)$ & $0.83(0.74-1.92)$ & I,635/7,393 (22.1) & $0.75(0.70-0.80)$ & $0.78(0.73-0.84)$ \\
\hline \multicolumn{7}{|l|}{ Education } \\
\hline $\begin{array}{l}\text { Above primary level } \\
(\geq \text { Grade } 8)\end{array}$ & I,I24/II,687 (9.6) & Reference & Reference & 2,709/II,687 (23.2) & Reference & Reference \\
\hline Below primary level ( & 55/47I (II.7) & $1.28(0.98-1.68)$ & $1.21(0.92-1.59)$ & $|23 / 47|(26 . \mid)$ & $1.23(1.02-1.47)$ & $1.40(1.16-1.68)$ \\
\hline \multicolumn{7}{|c|}{ Grade 8) } \\
\hline Unknown & 203/I,317 (I5.4) & $1.82(1.57-2.1 \mathrm{I})$ & $1.66(1.42-1.94)$ & $424 / 1,317(32.2)$ & $1.31(1.07-1.38)$ & $1.42(1.28-1.58)$ \\
\hline \multicolumn{7}{|l|}{ WHO stage } \\
\hline Stage I or II & 705/7,989 (8.8) & Reference & Reference & I,973/7,989 (24.7) & Reference & Reference \\
\hline Stage III or IV & $545 / 4,367(12.5)$ & $2.11(1.9-2.35)$ & $1.52(1.37-1.70)$ & I,048/4,367 (24.0) & $1.22(1.14-1.31)$ & $1.03(0.96-I .1 \mathrm{I})$ \\
\hline \multicolumn{7}{|c|}{ CD4 count (cells $/ \mathrm{mm}^{3}$ blood) } \\
\hline$\leq 100$ & $973 / 4,050(24.0)$ & Reference & Reference & I,767/4,050 (43.6) & Reference & Reference \\
\hline $10 \mid-200$ & $299 / 4,213(7.1)$ & $0.44(0.38-0.50)$ & $0.55(0.48-0.63)$ & $978 / 4,213(23.2)$ & $0.75(0.69-0.81)$ & $0.88(0.8 \mathrm{I}-0.95)$ \\
\hline $20 \mathrm{I}-350$ & $110 / 2,780(4.0)$ & $0.26(0.2|-0.3|)$ & $0.35(0.29-0.43)$ & $5 \mathrm{II} / 2,780(18.4)$ & $0.66(0.59-0.72)$ & $0.74(0.67-0.82)$ \\
\hline \multicolumn{7}{|l|}{ Hemoglobin (g/dL) } \\
\hline No anemia & $320 / 3,016(7.3)$ & Reference & Reference & $252 / 3,016(8.4)$ & Reference & Reference \\
\hline Mild anemia & $410 / 3,273(12.5)$ & $1.56(1.20-2.05)$ & $1.25(1.17-1.29)$ & 373/3,273 (1I.4) & $1.27(1.16-1.37)$ & $1.22(1.24-1.39)$ \\
\hline Moderate anemia & $481 / 4,492(10.7)$ & $1.34(1.18-1.97)$ & $1.13(1.08-1.20)$ & 489/4,492 (10.9) & $1.19(1.23-1.49)$ & $1.13(1.15-1.31)$ \\
\hline Severe anemia & $|7| / 969(17.7)$ & $2.14(1.90-2.35)$ & $1.47(1.31-1.64)$ & 268/969 (27.7) & $1.63(1.52-1.75)$ & 1.61 (I.49-1.73) \\
\hline \multicolumn{7}{|l|}{ BMI $\left(\mathrm{kg} / \mathrm{m}^{2}\right)$} \\
\hline$\geq 18.5$ & 699/9,06I (7.7) & Reference & Reference & I,868/9,06I (20.6) & Reference & Reference \\
\hline$<18.5$ & $683 / 2,773(24.6)$ & $2.40(2.15-2.66)$ & $1.76(1.58-1.98)$ & I,388/2,773 (50.0) & $2.03(1.89-2.18)$ & $1.35(1.25-1.45)$ \\
\hline
\end{tabular}

Notes: a Number of patients that died during the study; ${ }^{b}$ number of patients that were lost to follow-up. Reference $=1.00$.

Abbreviations: ART, antiretroviral therapy; $\mathrm{HR}$, hazard ratio; $\mathrm{Cl}$, confidence interval; $\mathrm{WHO}$, World Health Organization; $\mathrm{BMI}$, body mass index.

model using private physicians to treat and manage HIV using the South African DoH National ART treatment guidelines reported higher attrition rates in the private ART program. ${ }^{3}$ This could be because attrition was also inclusive of LTF in their study. We understand the difference in mortality rates between the two facilities to be a reflection of late entry to care (WHO clinical stage differences, differences in starting CD4 counts, and other comorbidities such as tuberculosis (TB) at ART initiation). Private clinic patients initiated treatment earlier, and did not have to wait until they met eligibility criteria which is a prerequisite in public sector ART programs. In addition, private patients may have had access to tertiary level care and alternative drug combinations that may result in greater tolerability, fewer side effects, better adherence, and a commitment to ART. While the doctors in the public sector are bound to follow South African DoH National ART treatment guidelines, the private sector is less rigid and more permissive of individualism. Concerns have been raised over issues of noncompliance and poor regulation of prescribing standards in the private sector. ${ }^{5,18}$ Drugs that are reserved as second-line regimens in the public sector are often used as first-line regimens in the private sector. The variations in prescribing practices in the private sector may be determined by relations between pharmaceutical companies and physicians. ${ }^{18}$ There is a need for standardizing HIV care and treatment in both sectors to conserve and maximize first-line ART regimens and reduce the need for expensive secondline treatment. Public-private partnerships can address the 
Table 4 Factors associated with failure to suppress viral load ( $\geq 400$ copies $/ \mathrm{mL})$ after 12 months of ART during the study period (July 2007-December 2012)

\begin{tabular}{|c|c|c|c|}
\hline Characteristic at baseline & $\begin{array}{l}N^{a}=I, 094, \text { data } \\
\text { shown as } n / N(\%)\end{array}$ & Crude RR $(95 \% \mathrm{Cl})$ & $\begin{array}{l}\text { Adjusted RR } \\
(95 \% \mathrm{CI})\end{array}$ \\
\hline \multicolumn{4}{|l|}{ Health facility } \\
\hline Public & $\mathrm{I}, 05 \mathrm{I} / \mathrm{I} 2,865(8.2)$ & Reference & Reference \\
\hline Private & $43 / 610(7.1)$ & $0.71(0.54-0.95)$ & $0.65(0.49-0.88)$ \\
\hline \multicolumn{4}{|l|}{ Age at initiation (years) } \\
\hline $18-29.9$ & $|90 / 2,33|(8.2)$ & Reference & Reference \\
\hline $30-39.9$ & $501 / 5,484(9.1)$ & $1.02(0.87-1.18)$ & $0.98(0.84-1.14)$ \\
\hline $40-49.9$ & $293 / 3,498(8.4)$ & $0.99(0.84-1.17)$ & $0.95(0.80-0.99)$ \\
\hline$\geq 50$ & $110 / 1,552(0.1)$ & $0.93(0.75-1.16)$ & $0.89(0.7 I-I .10)$ \\
\hline \multicolumn{4}{|l|}{ Sex } \\
\hline Female & $597 / 8,002(7.5)$ & Reference & Reference \\
\hline Male & $497 / 5,473(9.1)$ & $1.35(\mid .22-1.5 \mathrm{I})$ & $1.36(1.22-1.52)$ \\
\hline \multicolumn{4}{|l|}{ Education } \\
\hline Above primary level ( $\geq$ Grade 8) & $999 / 11,687(8.5)$ & Reference & Reference \\
\hline Below primary level (< Grade 8) & $33 / 47 \mid(7.0)$ & $0.92(0.67-1.27)$ & $0.96(0.70-1.32)$ \\
\hline Unknown & $62 / 1,317(4.7)$ & $0.80(0.63-1.02)$ & $0.80(0.63-1.04)$ \\
\hline \multicolumn{4}{|l|}{ CD4 count (cells/mm³ blood) } \\
\hline$\leq 100$ & $538 / 4,050(13.3)$ & Reference & Reference \\
\hline $10 \mid-200$ & $342 / 4,213(8.1)$ & $0.81(0.72-0.92)$ & $0.86(0.76-0.97)$ \\
\hline $20 \mathrm{I}-350$ & $214 / 2,780(7.7)$ & $0.94(0.8 \mathrm{I}-\mathrm{I} .08)$ & $1.00(0.87-1.16)$ \\
\hline \multicolumn{4}{|l|}{ Employment } \\
\hline Unemployed & $456 / 6,082(7.5)$ & Reference & Reference \\
\hline Employed & 638/7,393 (8.6) & $0.83(0.75-0.92)$ & $1.08(1.05-1.11)$ \\
\hline \multicolumn{4}{|l|}{ WHO stage } \\
\hline Stage I or II & $752 / 7,989(9.4)$ & Reference & Reference \\
\hline Stage III or IV & $342 / 4,367(7.8)$ & $0.99(0.88-1.1 \mathrm{I})$ & $0.90(0.80-1.02)$ \\
\hline \multicolumn{4}{|l|}{ Baseline BMI $\left(\mathrm{kg} / \mathrm{m}^{2}\right)$} \\
\hline$\geq 18.5$ & $768 / 9,061(8.5)$ & Reference & Reference \\
\hline$<18.5$ & $326 / 2,773(11.8)$ & $1.27(1.14-1.44)$ & $1.23(1.09-1.39)$ \\
\hline \multicolumn{4}{|l|}{ Baseline hemoglobin (g/dL) } \\
\hline No anemia & $27 \mid / 3,016(9.0)$ & Reference & Reference \\
\hline Mild anemia & $298 / 3,273(9.1)$ & $1.00(0.87-1.05)$ & $1.03(0.92-1.13)$ \\
\hline Moderate anemia & $401 / 4,492(8.9)$ & $0.98(0.79-1.11)$ & $1.01(0.96-1.19)$ \\
\hline Severe anemia & $124 / 969(12.8)$ & $1.12(0.96-1.26)$ & $1.14(1.00-1.29)$ \\
\hline
\end{tabular}

Notes: ${ }^{a}$ Number of patients that had an elevated viral load ( $\geq 400$ copies $/ \mathrm{mL}$ after 12-month post-ART initiation). Reference $=1.00$.

Abbreviations: ART, antiretroviral therapy; RR, risk ratio; $\mathrm{Cl}$, confidence interval; WHO, World Health Organization; BMI, body mass index.

issues of noncompliance and lack of standardized care in the private sector. This coalition also has the potential to address inadequacies of the public sector such as staff shortages, patient stigmatization, and drug shortages. ${ }^{19}$

For both facilities, mortality rates were high in the first 6 months of ART initiation. This observation is consistent with literature, with some authors reporting peaks in the first 12 months of ART. ${ }^{20}$ This could also reflect the occurrence of immune reconstitution inflammatory syndrome (IRIS), which necessarily worsens the nature of disease and the response to treatment in the HIV-infected patient with opportunistic disease. ${ }^{21,22}$ This emphasizes the need for early identification of high-risk groups and early initiation of ART to prevent early mortality, especially in the public sector where the majority of patients initiate with advanced HIV.
We demonstrate that CD4 count, WHO clinical stage IV, and nutritional status (BMI and anemia) at ART initiation are significant predictors of mortality. These findings have also been reported elsewhere. ${ }^{20-25}$

\section{Loss to follow-up}

The rate of LTF was higher in the private clinic, with rates increasing with ART duration. Research have shown that LTF is very common in the private sector, where patients with HIV often have to pay for all HIV-related services as well as treatment. ${ }^{4,5,26}$ The ability of patients within the South African private sector health program to continue to pay their monthly medical aid contributions may be difficult for those whose income and whose commitments to household debt are marginal at best. Unlike the public sector where patients 
are usually obliged to go to one clinic, patients in the private sector may move to a different doctor for various reasons. This could also explain the high rates of loss from the private clinic in this study. In the public sector, intensive efforts are made to follow-up on patients before they are confirmed lost from the program. ${ }^{27}$

Our results showed that retention rates increased with age (young adults are more likely to be lost from ART programs than older patients). Similar findings have been reported by other studies. $^{23,26,28}$ This is consistent with the observation that younger, unemployed patients are likely to be lost from programs. Adults are likely to be employed, an important trait in the private health sector where there is a profound need for financial stability in ART provision. In the public sector, young unemployed adults may be lost due to lack of transport money to ART clinics. However, decentralization of care initiatives seems to be addressing such issues. ${ }^{29}$

\section{Immunological and virological responses at 12 months of ART}

Better virological outcomes were observed in the private clinic as indicated by a greater proportion of patients that had a suppressed viral load at 12 months of ART in this clinic.

Higher absolute median CD4 changes were also recorded in the private clinic. Male patients were more likely to have poor virological outcomes. This finding suggests that stakeholders in ART programs need to incorporate male-friendly services targeted at this population to improve treatment outcomes. Close monitoring of the nutritional status of patients is important because our findings suggest that patients who were underweight or anemic were more likely to fail to suppress their viral load at 12 months on ART.

\section{Limitations}

The data used during the study were from one public ART clinic and one private ART clinic located in Johannesburg. The public clinic is a tertiary clinic supported by experts in HIV management. Hence, general outcomes would be expected to be better than an average public sector HIV clinic. Similarly, the private sector clinic is a dedicated HIV clinic run by an experienced HIV clinician. In addition, HIV management in the developed world is different from the limited resource countries. Consequently, the generalizability of findings to all settings is limited.

The findings of the study should be considered in light of other limitations namely small sample size of private patients relative to the public patients, missing data, and differences in data collection (data were prospectively collected after
2012 in the private clinic, while real-time data collection started as early as 2009 at TLC), differences in prescribing practices, CD4 count, and viral load monitoring between the two sectors and lack of data on adherence and viral resistance from both facilities. In addition, calculated vs actual LTF was determined, and this could have overestimated LTF rates in the study. At baseline, missing data ranged from $2.4 \%$ to $20.4 \%$ for the private clinic and from $8.4 \%$ to $18.3 \%$ for the public clinic. At 12 months, 45\% (110/245) of patients in the private clinic and $55 \%(3,590 / 6,528)$ of patients in the public clinic did not have a viral load. We conducted a sensitivity analysis to investigate the effect of missing viral load values and did not observe a difference. In addition, we compared baseline characteristics of those with a missing viral load and those with a viral load at 12-month post-ART initiation and found no difference in age, education, baseline hemoglobin, and WHO stage $(P>0.05)$ suggesting that viral load is missing at random and the results for those with a viral load measurement are representative of the entire study population. LTF may have led to a misclassification of mortality as LTF. Despite active patient tracing, mortality is substantially underestimated among HIV-positive patients lost from HIV treatment programs. Where possible and with valid national identification numbers, mortality was obtained and verified against the South African National Vital Registration system, which provides a more accurate assessment of mortality.

\section{Conclusion}

Findings from this study suggest that the type of health facility in which patients access ART can have an impact on treatment outcomes. In our study, both positive and negative outcomes were identified from either sector. Further research is recommended to provide more conclusive evidence.

\section{Acknowledgments}

We thank the directors of $\mathrm{HE}^{2} \mathrm{RO}$ and Right to Care for administrative and technical support. We are grateful to Themba Lethu Clinic at Helen Joseph Hospital and the private clinic for providing care for the study patients and most importantly, we thank the patients for allowing us to use their data. This study was made possible by the generous support of the Americans through Cooperative Agreement AID 674-A-12-00029 and Innovative Research on AIDS (INROADS) from the US Agency for International Development (USAID). The contents are the responsibility of the authors and do not necessarily reflect the views of USAID or the US Government. LL, IMS, ATB, FM, and DE were 
funded by this Cooperative Agreement. Any opinion, finding, and conclusion or recommendation expressed in this material is that of the author(s) and the USAID does not accept any liability in this regard.

The abstract of this paper was presented at the AIDS 2014 Conference as a poster presentation with interim findings. The poster's abstract was published in "Poster Abstracts" in the AIDS 2014 Conference website: http://pag.aids2014.org/ EPosterHandler.axd?aid=4687.

\section{Disclosure}

The authors report no conflicts of interest in this work.

\section{References}

1. Nglazi MD, Lawn SD, Kaplan R, et al. Changes in programmatic outcomes during 7 years of scale-up at a community-based antiretroviral treatment service in South Africa. BMC Infect Dis. 2011;56(1):e1-e8.

2. Shah B, Walshe L, Saple DG, et al. Adherence to antiretroviral therapy and virologic suppression among HIV-infected persons receiving care in private clinics in Mumbai, India. Clin Infect Dis. 2007;44(9):1235-1244.

3. Innes C, Hamilton R, Hoffman CJ, et al. A novel HIV treatment model using private practitioners in South Africa. Sex Transm Infect. 2012;88(2):136-140.

4. Stevensi M, Sinanovici E, Regenesbergi L, Hislopii M. HIV and AIDS, STIs and TB in the private sector, 2010. Available from: http://fullnulled. com/doc/pdf/download/www_hst_org_za-uploads-files-chap14_07.pdf. Accessed December 21, 2015.

5. Shet A, DeCosta A, Heylen E, Shastri S, Chandy S, Ekstrand M. High rates of adherence and treatment success in a public and public-private HIV clinic in India: potential benefits of standardized national care delivery systems. BMC Health Serv Res. 2011;11:277.

6. Govindasamy D, Ford N, Kranzer K. Risk factors, barriers and facilitators for linkage to antiretroviral therapy care: a systematic review. AIDS. 2012;26(23):2059-2067.

7. Bekker LG, Venter F, Cohen K, et al. Provision of antiretroviral therapy in South Africa; the nuts and bolts. Antivir Ther. 2014;19(3);105-116.

8. Fox MP, Brennan A, Maskew M, MacPhail P, Sanne I. Using vital registration data to update mortality among patients lost to follow-up from ART programmes: evidence from the ThembaLethu Clinic, South Africa. Trop Med Int Health. 2010;15(4):405-413.

9. Sanne IM, Westreich D, Macphail AP, Rubel D, Majuba P. Long term outcomes of antiretroviral therapy in a large HIV/AIDS care clinic in urban South Africa: a prospective cohort study. J Int AIDS Soc. 2009;12:38.

10. Nglazi MD, Kranzer K, Holele P, Kaplan R, Mark D, Jaspan H. Treatment outcomes in HIV-infected adolescents attending a community-based antiretroviral therapy clinic in South Africa. BMC Infect Dis. 2012;12(21):1471-2334.

11. Fox MP, Maskew M, MacPhail AP, et al. Cohort profile: the Themba Lethu Clinical Cohort, Johannesburg, South Africa. Int J Epidemiol. 2013;42(2):430-439

12. Scaling up antiretroviral therapy in resource-limited settings: Treatment guidelines for a public health approach 2004. Available from: http:// www.who.int/hiv/pub/prev_care/en/arvrevision2003en.pdf?ua=1. Accessed December 21. 2015.

13. Antiretroviral therapy for HIV infection in adults and adolescents: Recommendations for a public health approach 2010. Available from: http://www.ncbi.nlm.nih.gov/books/NBK138523\#ch11.s1. Accessed December 21, 2015.
14. National antiretroviral treatment guidelines 2004. Available from: http:// www0.sun.ac.za/ruralhealth/ukwandahome/rudasaresources2009/ DOH/1.\%20Antiretroviral.pdf. Accessed December 22, 2015.

15. South African National Department of Health Antiretroviral Therapy Guidelines 2010. Available from: http://www.fidssa.co.za/ Guidelines/2010_Adult_ART_Guidelines.pdf. Accessed October 01, 2014.

16. Shearer K, Brennan AT, Maskew M, et al. The relation between efavirenz versus nevirapine and virologic failure in Johannesburg, South Africa. J Int AIDS Soc. 2014;17:19065.

17. Westreich D, Maskew M, Evans D, Firnhaber C, Majuba P, Sanne I. Incident pregnancy and time to death or AIDS among HIV-positive women receiving antiretroviral therapy. PLoS One. 2013;8(3):e58117

18. Gounden R. A clinical assessment of antiretroviral-treated patients referred from the private sector to the South African government antiretroviral (ARV) programme: a retrospective analysis. South Afr J HIV Med. 2011;12(1):8-14

19. John S, Johnson J, Majorowski M, Friedman N, Blazer C. Private sector involvement in HIV service provision. Arlington VA: US SAID|AIDSTAR-One Project Task Force Order 1. 2009. Available from: http://www.jsi.com/JSIInternet/Resources/publication/display.c fm?txtGeoArea=INTL\&id=11211\&thisSection=Resources. Accessed July 222014.

20. Somi G, Keogh SC, Todd J, et al. Low mortality risk but high loss to follow-up among patients in the Tanzanian national HIV care and treatment programme. Trop Med Int Health. 2012;17(4):497-506.

21. Lawn SD, Harries AD, Anglaret X, Myer L, Wood R. Early mortality among adults accessing antiretroviral treatment programmes in subSaharan Afr. J AIDS. 2008;22:1897-1908.

22. Zachariah R, Harries K, Moses M, et al. Very early mortality in patients starting antiretroviral treatment at primary health centres in rural Malawi. Trop Med Int Health. 2009;14(7):713-721.

23. Mosha F, Muchunguzi V, Matee M, et al. Gender differences in HIV disease progression and treatment outcomes among HIV patients one year after starting antiretroviral treatment (ART) in Dares Salaam, Tanzania. BMC Public Health. 2013;13:38.

24. World Health Organization. Disease Staging System for HIV Infection and Disease; 2006. Available from: http://www.who.int/hiv/pub/ guidelines/clinicalstaging.pdf. Accessed April 5, 2014.

25. Stringer J, Zulu I, Levy J, et al. Rapid scale-up of antiretroviral therapy at primary care sites in Zambia: feasibility and early outcomes. $\mathrm{J} \mathrm{Am}$ Med Assoc. 2006;296(7):782-793.

26. Moshabela M, Schneider H, Cleary SM, Prony P, Eyles J. Does accessibility to antiretroviral care improve after down referral of patients from hospitals to health centres in South Africa? Af J AIDS. 2011;10(4): 393-401

27. Cornell M, Grimsrud A, Fairall L, et al. Temporal changes in programme outcomes among adult patients initiating antiretroviral therapy across South Africa, 2002-2007. J AIDS. 2010;24(14):2263-2270.

28. Maskew M, Brennan AT, Macphail AP, Sanne IM, Fox MP. Poorer ART outcomes with increasing age at a large public sector HIV clinic in Johannesburg, South Africa. J Int Assoc Physicians AIDS Care. 2012;11(1):57-65.

29. Harries AD, Zachariah R, Lawn SD, Rosen S. Strategies to improve patient retention on antiretroviral therapy in sub-Saharan Africa. Trop Med Int Health. 2010;15(1):70-75.

30. Evans D, Menezes C, Mahomed K, et al. Treatment outcomes of HIV-infected adolescents attending public-sector HIV clinics across Gauteng and Mpumalanga, South Africa. AIDS Res Hum Retroviruses. 2013;29(6):892-900. 


\section{Publish your work in this journal}

Clinical Epidemiology is an international, peer-reviewed, open access, online journal focusing on disease and drug epidemiology, identification of risk factors and screening procedures to develop optimal preventative initiatives and programs. Specific topics include: diagnosis, prognosis, treatment, screening, prevention, risk factor modification,

Submit your manuscript here: http://www.dovepress.com/clinical-epidemiology-journal
Dovepress

systematic reviews, risk \& safety of medical interventions, epidemiology \& biostatistical methods, and evaluation of guidelines, translational medicine, health policies \& economic evaluations. The manuscript management system is completely online and includes a very quick and fair peer-review system, which is all easy to use. 